\title{
Combination of Fractional Exhaled Nitric Oxide (FeNO) Level and Asthma Control Test (ACT) in Detecting GINA-Defined Asthma Control in Treated Asthmatic Patients in Vietnam
}

\author{
Vinh Nguyen Nhu $\mathbb{D}^{1,2,3}$ Pham Le An, ${ }^{2}$ and Niels H. Chavannes ${ }^{1}$ \\ ${ }^{1}$ Department of Public Health and Primary Care, Leiden University Medical Center, Leiden, Netherlands \\ ${ }^{2}$ Department of Family Medicine, Faculty of Medicine, University of Medicine and Pharmacy at Ho Chi Minh City, Vietnam \\ ${ }^{3}$ Department of Respiratory Functional Exploration, University Medical Center, Ho Chi Minh City, Vietnam
}

Correspondence should be addressed to Vinh Nguyen Nhu; vinhnguyenmd@ump.edu.vn

Received 3 October 2019; Revised 27 February 2020; Accepted 28 February 2020; Published 25 April 2020

Academic Editor: Michael Roth

Copyright (c) 2020 Vinh Nguyen Nhu et al. This is an open access article distributed under the Creative Commons Attribution License, which permits unrestricted use, distribution, and reproduction in any medium, provided the original work is properly cited.

\begin{abstract}
Background. FeNO has been used as a marker for Th2-mediated airway inflammation in asthma. There is evidence which recommends the use of this biomarker in asthma management. Little is known about whether the FeNO test alone or in combination with the ACT score can reflect asthma control in Vietnamese patients. Materials and Methods. A cross-sectional study was conducted in asthmatic patients ( $\geq 18$ years old) recruited at the University Medical Center, Ho Chi Minh City, Vietnam from March 2016 to March 2017. Asthma control levels were assessed following the GINA 2017 guidelines, and FeNO was measured by a Niox Mino device. FeNO cut-offs predicting asthma control status were determined using the ROC curve analysis. The combination of FeNO and ACT was investigated in detecting well-controlled and uncontrolled asthma. The results of the study are as follows: 278 patients with $68 \%$ females, mean age of 44 years, and mean asthma duration of 10 years were analyzed. All patients were treated following step 2 to 4 of GINA guidelines. Mean (SD) FeNO was 30.6 (24) ppb. Patients with uncontrolled (16\%), partly controlled (29\%), and well-controlled asthma (55\%) had a median (IQR) FeNO of 50.0 (74), 25.0 (23), and 21.0 (22.3) $\mathrm{ppb}$, respectively, and the mean of FeNO in the uncontrolled group was significantly higher than that in other groups $(p<0.001)$. The area under the ROC curve (AUC) for FeNO detecting uncontrolled asthma was 0.730 with an optimal cut-off point of FeNO $>50 \mathrm{ppb}$, and this AUC increased to 0.89 when combining FeNO and ACT. The AUC for FeNO detecting well-controlled asthma was 0.601 with an optimal cut-off point of FeNO $<25 \mathrm{ppb}$ and this AUC increased to 0.78 if combining FeNO and ACT. Conclusions. FeNO can predict asthma control status with an estimated cut-off point of $<25 \mathrm{ppb}$ for well-controlled and $>50 \mathrm{ppb}$ for uncontrolled asthma. The combination of FeNO and ACT provides better information regarding asthma control than FeNO alone, and this combination is useful to predict asthma control statuses in asthmatic patients in Viet Nam.
\end{abstract}

\section{Introduction}

Recent asthma guidelines have recommended using a control-based strategy to manage asthma patients with the goal of helping them achieve and maintain disease control, which requires the suppression of airway inflammation by inhaled corticosteroids (ICS) or other medications [1]. In addition, although published evidence is still controversial, many clinical trials were conducted and indicated that the strategy of asthma management based on or combined with the FeNO test could provide better outcomes than based on symptoms and lung function only [2-4]. In Vietnam, the FeNO test has been developed recently, and this biomarker is emerging to be used in asthma management in this country. However, whether this biomarker reflects asthma control in Vietnam is still not yet determined although the literature reported that it was a weak correlation between FeNO and asthma control level [5]. Therefore, before FeNO being used widely in Vietnam for asthma management, its value (alone or combination with other parameters) in reflecting asthma 
control should be investigated. Thus, the aim of this study is to determine the value of FeNO alone or combined with ACT in reflecting GINA-defined asthma control.

\section{Patients and Methods}

2.1. Study Design and Setting. This was a prospective crosssectional study. Eligible participants were ambulatory adult patients ( $\geq 18$ years old) (recruited between March 2016 and March 2017) at the University Medical Center Asthma and COPD clinic, Ho Chi Minh City, Vietnam.

2.2. Ethical Approval. The study protocol was approved by the Institutional Review Board of the University of Medicine and Pharmacy, Ho Chi Minh City, Vietnam. All patients were given a written informed consent form, and those who participated in this study had to sign this consent form.

2.3. Inclusion and Exclusion Criteria. Patients eligible for inclusion in this study were $\geq 18$ years old, diagnosed with asthma at least 6 months previously according to the GINA 2015 criteria (had asthma symptoms and evidence of bronchodilator reversibility test-FEV1 change $\geq 12 \%$ and $200 \mathrm{ml}$ after inhalation of 4 puffs ( $400 \mathrm{mcg}$ ) salbutamol-of Ventolin ${ }^{\circledR}$ ), and followed up at this clinic. Patients were excluded if meeting any of the following exclusion criteria: hospitalized for asthma or had an acute upper or lower respiratory tract infection within 4 weeks prior to the study, had a known respiratory disorder other than asthma and/or systemic/thoracic abnormalities that influence normal lung function, current smoker or ex-smoker with $>10$ pack-years, and did not undergo their treatment for more than 2 weeks within 3 months prior to the study.

2.4. Sample Size and Sampling Technique. With a presumption based on the literature that FeNO can detect GINA-defined uncontrolled (UC) asthma with a specificity of $80 \%$ [6], the calculated sample size was 246 subjects.

\subsection{Data Collection and Classification}

(i) Asthma control is classified into the following 3 levels: well-controlled (WC), partly controlled (PC), and uncontrolled (UC) based on GINA 2017 guidelines as given in Table 1.

(ii) FeNO measurement: FeNO level was measured by a Niox Mino device (Aerocrine AB, Solna, Sweden) at a flow rate of $50 \mathrm{~mL} / \mathrm{s}$ for 10 seconds following the manufacturer's manual $[7,8]$. FeNO measurement was followed to the ATS/European Respiratory Society (ERS) 2005 recommendations [9]. Participants indicated for FeNO measurement underwent this test prior to a spirometry test to avoid interfering the spirometry results. FeNO values were graded into the following 3 levels: low ( $<25 \mathrm{ppb})$, intermediate $(25-50 \mathrm{ppb})$, and high ( $>50 \mathrm{ppb}$ ) following the American Thoracic Society (ATS) categorization [10]. (iii) Asthma Control Test (ACT): This test comprises five questions assessing the frequency of shortness of breath, frequency of asthma night-time symptoms, degree of functional limitation, frequency of using rescuers, and patient's self-assessment of their level of asthma control. Each item has five response choices (each with a score ranging from 1-5). Accordingly, the levels of asthma control are as follows: well-controlled (scores of 20-25), partially controlled (15-19), and uncontrolled (5-14) [27]. The Vietnamese version of this questionnaire was validated [28] and used for the present study.

(iv) Spirometry: The spirometry test was conducted by using a KoKo spirometer (nSpire Health, Longmont CO 80501, USA) following the manufacturer's instructions [11]. Devices' calibration and patients' preparation before the measurement were conducted following the guidance of ERS/ATS 2005 [12]. Participants performed spirometry after FeNO measurement. Spirometry variables used in this study comprise of FEV1 \% predicted (\%FEV1) and PEF\% predicted $(\% \mathrm{PEF})$, which are commonly used in asthma monitoring.

2.6. Data Analysis. Data were processed with Epidata software and analyzed using SPSS software. Continuous variables are presented depending on their distribution as means and standard deviations (SD) for normal distribution or median and interquartile range (IQR) for nonnormal distribution. Ordinal and nominal variables are presented as numbers and percentages. The chi-square statistic was used for testing relationships between categorical variables. Student's $t$-test and ANOVA test were used to compare the means of two groups or more, respectively, for normally distributed data (such as FEV1). The Mann-Whitney $U$ test and the Kruskal-Wallis test were used to compare the median of two groups or more, respectively, for nonnormally distributed data (such as FeNO). If a comparison of multiple groups provides significant difference, the post hoc analysis then was used for pair-wise comparison of post hoc ANOVA with the Tamhane test-because of unequal variances-for parametric test and the Mann-Whitney $U$ test for nonparametric test. The receiver operating curve (ROC) analysis was used to distinguish WC asthma and UC asthma by FeNO levels or a combination of FeNO and ACT as well as identify cutoff points with an optimal sensitivity (true-positive rate) and specificity (true-negative rate) using the highest Youden index. Positive predictive value (PPV), negative predictive value (NPV), positive likelihood ratio (PLR), negative likelihood ratio (NLR), and accuracy of the test were also calculated. A $p$ value $\leq 0.05$ was considered statistically significant.

\section{Results}

3.1. Characteristics of Study Patients. A number of patients were recruited and analyzed as shown in the flowchart (Figure 1). 
TABLe 1: Global Initiative for Asthma (GINA) definitions of asthma control.

\begin{tabular}{llrl}
\hline Asthma symptom control & & \multicolumn{2}{c}{ Level of asthma symptom control } \\
In the past 4 weeks, has the patient had & Well-controlled & Partly controlled \\
\hline Daytime asthma symptoms more than twice/week? & Yes $\square$ No $\square$ & & Uncontrolled \\
Any night waking due to asthma? & Yes $\square$ No $\square$ & None of these & 1-2 of these \\
$\begin{array}{l}\text { Reliever needed for symptoms* more than twice/week? } \\
\text { Any activity limitation due to asthma? }\end{array}$ & $\begin{array}{l}\text { Yes } \square \text { No } \square \\
\text { Yes } \square \text { No } \square\end{array}$ & \\
\hline
\end{tabular}

Totally, 278 eligible subjects were inputted into the study analysis after 300 patients being invited (93\%). The demographic data of the study subjects are given in Table 2. In the present study, almost all patients received ICS with or without combining with long-acting beta2-agonists (LABA). Most of the subjects were classified as WC group (55\%). The present study have objectives to detect GINA-defined asthma control (UC and WC); thus, comparisons of many characteristics of the study participants according to the levels of GINA asthma control are presented in Tables 2 and 3 and Figures 2 and 3. The shortest and longest durations of asthma were 6 months and 73 years, respectively. Thirty-nine patients (14\%) reported acquiring asthma from childhood. The mean (SD) and median (IQR) FeNO level of the study subjects were $30.6 \mathrm{ppb}$ (24) and $24 \mathrm{ppb}$ (26.3), respectively.

The prevalence of patients with FeNO corresponding to three levels following the American Thoracic Society (ATS) categorization [10] were 51\% (low), 32\% (intermediate), and $17 \%$ (high), respectively. The distribution of patients with different levels of asthma control according to FeNO levels is shown in Figure 2 . There are only $31(11 \%)$ of patients with WC asthma but nearly a half of the UC asthmatic patients (48.8\%) had high FeNO levels. Most of the WC patients with asthma (59.7\%) and one-fourth (25.6\%) of the UC patients with asthma had low FeNO levels. On the other hand, most patients (46\%) with high FeNO level had UC asthma, while most patients (64\%) with low FeNO level had WC asthma.

Levels of asthma control may be contributed by many factors in which severity of the disease and its treatment play an important role. FEV1 \% predicted (\%FEV1) is still a component of asthma severity, and the distribution of this parameter in different asthma control levels is given in Table 3. 16.3\% UC asthma patients had \%FEV1 less than $60 \%$ and that of the percentage in the $\mathrm{PC}$ and $\mathrm{WC}$ groups are quite low $(7.4 \%$ and $1.3 \%)$. Most WC patients $(83,8 \%)$ had normal \%FEV1 (\%FEV1 $\geq 80 \%)$.

Regarding asthma treatment, the prevalence of patients who were on GINA treatment steps $1,2,3,4$, and 5 were $0 \%$, $22.3 \%, 31.2 \%, 45.7 \%$, and $0 \%$, respectively. Table 3 shows different percentage of asthma treatment levels according to asthma control status. Most of the UC patients (67.4\%) were treated with GINA treatment step 4, and many patients (32.5\%) with WC asthma were treated with GINA treatment step 2. In terms of medications use, most patients (56.1\%) used a combination of ICS, long-acting beta2-agonists (LABA), and montelukast for their treatment, and the number of participants who used this combination in the UC group (74.4\%) significantly differs from those in the PC group $(60.5 \%)$ and the WC group (48.7\%). Monotherapy

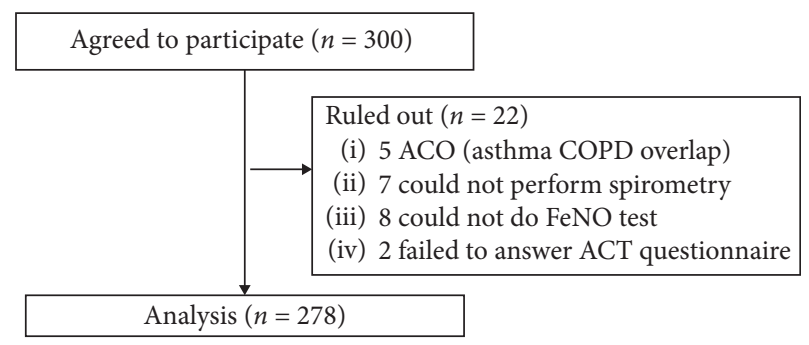

FIGURE 1: Flowchart of number of patients recruited and analyzed in this study.

with ICS or montelukast was mostly used by the WC group (21.4\%).

To compare whether FeNO is different among the three groups of patients who had different asthma control status. Figure 3 provides information that the median of FeNO in the UC group (50 ppb) is significantly higher than those in the PC group (25 ppb) and the WC group (21 ppb), $p<0.001$. However, there is no significant difference in the medians of FeNO between the PC group and the WC group $(p=0.446)$.

The values of FeNO to classify patients with asthma following GINA-defined control asthma status are shown in Figure 4. The area under the ROC curve (AUC) in prediction of GINA-defined UC asthma is 0.730 (95\% CI: $0.637-0.823 ; p<0.001$, Figure $4(\mathrm{a}))$. With the cut-off point of FeNO $>50 \mathrm{ppb}$, the maximum Youden index is 0.401 and FeNO levels could detect UC asthma with the sensitivity of $51 \%$ and the specificity of $89 \%$, PPV $46 \%$, NPV 91\%, PLR 4.6, NLR 0.54, and accuracy 0.6. This cut-off point coincides with the high level of FeNO as per the ATS categorization $(\mathrm{FeNO}>50 \mathrm{ppb})[10]$. The AUC in prediction of GINA-defined WC asthma is 0.601 (95\% CI: 0.534-0.668; $p=0.004$, Figure 4(b)). With the cut-off point of FeNO $<25 \mathrm{ppb}$, the maximum index of Youden is 0.186 and FeNO levels could detect WC asthma with the sensitivity of $59 \%$ and the specificity of $60 \%$, PPV $64 \%$, NPV 54\%, PLR 1.5, NLR 0.7, and accuracy 0.6. Although this cut-off point has low predicted value, it also coincides with the ATS-defined low level of FeNO (FeNO $<25 \mathrm{ppb}$ ) [10] The results indicate that although our suggested cutoff point of FeNO level detecting WC asthma is similar with the ATS classification, our suggested predicted valuesare still low.

In combination of FeNO and ACT, the AUC of this combination in detecting UC asthma and WC asthma was 0.890 (95\% CI: 0.841-0.939; $p<0.001$, Figure 5(a)) and 0.779 (95\% CI: 0.716-0.827; $p<0.001$, Figure 5(b)), respectively. 
TABLE 2: Clinical characteristics of the study subjects according to asthma control status.

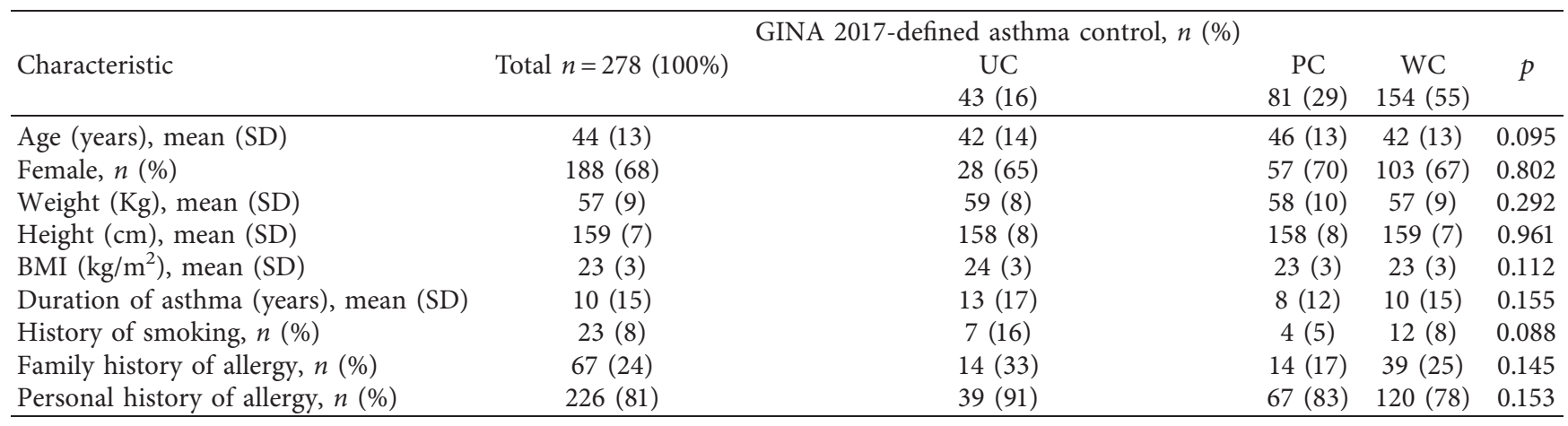

UC, uncontrolled; PC, partly controlled; WC, well-controlled; BMI, body mass index; SD, standard deviation; FeNO, fractional exhaled nitric oxide; FEV1, forced exhaled volume in 1 second; $\mathrm{P}, p$ value of comparison of 3 groups which had different levels of asthma control by the chi-square test; \%, percentage counted by column.

TABLE 3: The distribution of patients in different levels of asthma control according to FEV1 \% predicted, GINA treatment steps, and medication use.

\begin{tabular}{|c|c|c|c|c|c|c|}
\hline \multirow{2}{*}{ Characteristic } & \multirow{2}{*}{ Category } & \multicolumn{4}{|c|}{ GINA 2017-defined asthma control, $n(\%)$} & \multirow{2}{*}{$p$} \\
\hline & & UC & PC & WC & Total & \\
\hline \multirow{4}{*}{$\% F E V 1$} & $<60 \%$ & $7(16.3)$ & $6(7.4)$ & $2(1.3)$ & $15(5.4)$ & \multirow{4}{*}{$<0.001$} \\
\hline & $60-79.9 \%$ & $18(41.9)$ & $29(35.8)$ & $23(14.9)$ & $70(25.2)$ & \\
\hline & $\geq 80 \%$ & $18(41.9)$ & $46(56.8)$ & $129(83.8)$ & $193(69.4)$ & \\
\hline & Total & $43(100)$ & $81(100)$ & $154(100)$ & $278(100)$ & \\
\hline \multirow{4}{*}{ GINA treatment steps } & Step 2 & $5(11.6)$ & $7(8.6)$ & $50(32.5)$ & $62(22.3)$ & \multirow{4}{*}{$<0.001$} \\
\hline & Step 3 & $9(20.9)$ & $32(39.5)$ & $48(31.2)$ & $48(31.2)$ & \\
\hline & Step 4 & $29(67.4)$ & $42(51.9)$ & $127(45.7)$ & $127(45.7)$ & \\
\hline & Total & $43(100)$ & $81(100)$ & $154(100)$ & $278(100)$ & \\
\hline \multirow{6}{*}{ Medication use } & Montelukast & $1(2.3)$ & $1(1.2)$ & $4(2.6)$ & $6(2.2)$ & \multirow{6}{*}{0.003} \\
\hline & ICS & $2(4.7)$ & $2(2.5)$ & $29(18.8)$ & $33(11.9)$ & \\
\hline & ICS + montelukast & $1(2.3)$ & $2(2.5)$ & $8(5.2)$ & $11(4.0)$ & \\
\hline & $\mathrm{ICS}+\mathrm{LABA}$ & $7(16.3)$ & $27(33.3)$ & $38(24.7)$ & $72(25.9)$ & \\
\hline & $\mathrm{ICS}+\mathrm{LABA}+$ montelukast & $32(74.4)$ & $49(60.5)$ & $75(48.7)$ & $156(56.1)$ & \\
\hline & Total & $43(100)$ & $81(100)$ & $154(100)$ & $278(100)$ & \\
\hline
\end{tabular}

UC, uncontrolled; PC, partly controlled; WC, well-controlled; FEV1, forced exhaled volume in 1 second; GINA, global initiative for asthma; ICS, inhaled corticosteroid; LABA, long-acting beta2-agonist; P, $p$ value of comparison of 3 groups had different levels of asthma control by the chi-square test; \%, percentage counted by column.

Using a combination of FeNO and ACT with usual cutoff points such as FeNO $>50 \mathrm{ppb}$ and $\mathrm{ACT}<20$ points as an indicator for UC asthma, the value of this combination in predicting UC asthma is described in Table 4. From this table, the sensitivity, specificity, PPV, NPV, PLR, and NLR were calculated as $40 \%, 96 \%, 63 \%, 90 \%, 10$, and 0.6 , respectively. On the other hand, if using the cut-off point of the combination $(\mathrm{FeNO}<25 \mathrm{ppb}$ and $\mathrm{ACT} \geq 20)$ as an indicator for WC asthma, the value of this combination in predicting WC asthma were sensitivity, specificity, PPV, NPV, PLR, and NLR as $49 \%, 84 \%, 79 \%, 57 \%, 3$, and 0.6 , respectively, calculated from the values given in Table 5 .

\section{Discussion}

The main findings of the present study are that FeNO levels in Vietnamese adults with asthma were significantly different according to asthma control status during treatment, although with broad overlaps. Moreover, it showed that the combination of FeNO and ACT provides a better method in detecting UC and WC asthma although FeNO alone may detect UC and WC asthma with cut-off points similar with the high and low thresholds of FeNO levels as recommended by the ATS [10].

Asthma control may be formed by many components such as duration of disease, history of smoking, allergic problems, disease's severity, dose of treatment, and patients' adherence. All these factors are given in Tables 2 and 3 except adherence.

The information of adherence was not collected in detail in the present study; however, it is believed that almost all participants in this study follow their treatment strictly due to the following reasons. The study clinic is specialized in asthma and COPD management located in a teaching hospital; therefore, the model of its asthma management is standardized. There are 4 barrier layers which protect patients from incorrect usage of inhaler devices in this clinic: (i) giving general guidance on how to use the devices by doctors in examination room, (ii) guiding patients to use their real medications (after getting from hospital's pharmacy) by 


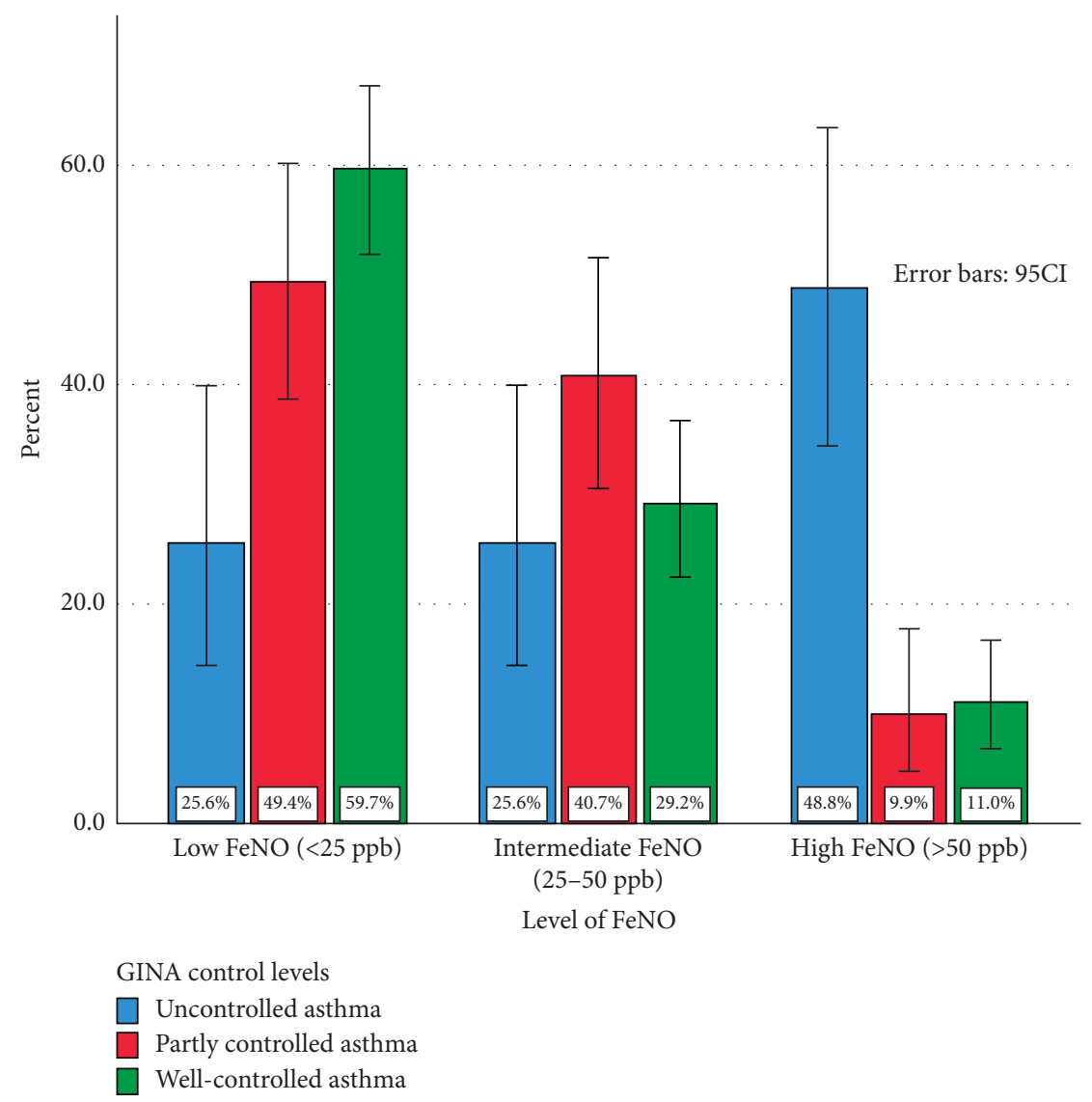

FIgure 2: The distribution of patients in different levels of asthma control according to the FeNO level classification following the ATS categorization, $p<0.001$.

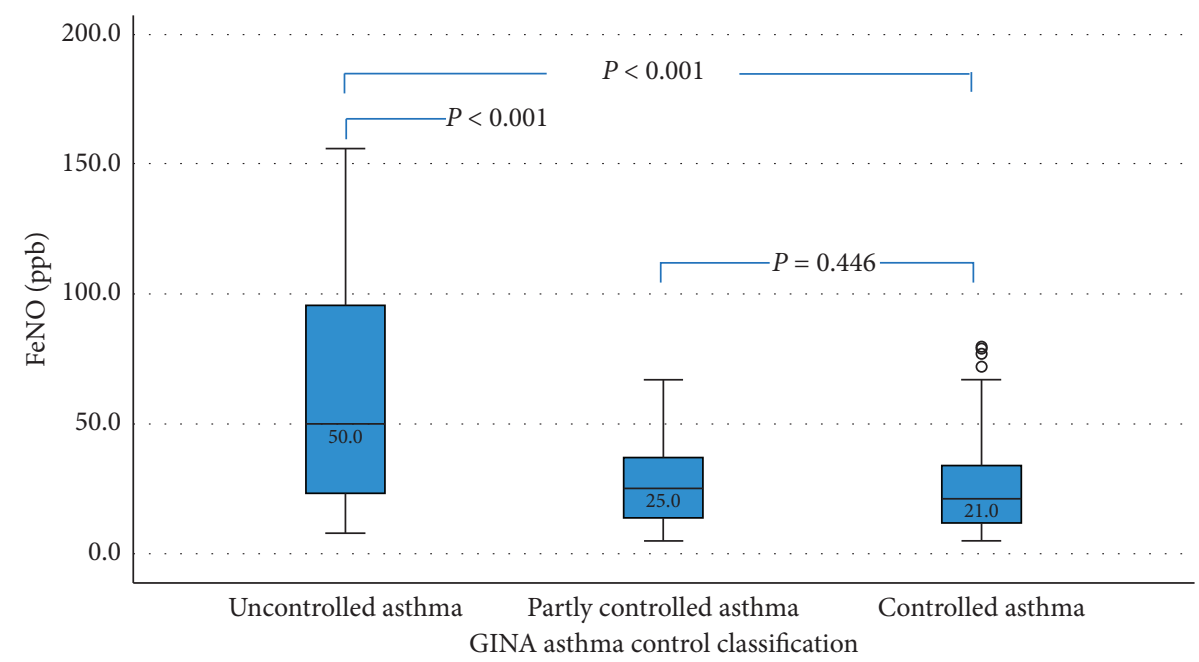

FIGURE 3: The median of fractional exhaled nitric oxide (FeNO) levels in patients with different asthma control status according to the GINA guidelines.

nurses at reception area, (iii) checking patients with their real performance with their old medications by spirometry technicians, whenever the patients were send to the spirometry room, and (iv) showing how to use medications by clips on TV in the waiting room. Furthermore, those patients who did not use their medications for more than 2 weeks within 3 months prior to the study were ruled out as mentioned in the exclusion criteria. With all of the above information, it is believed that adherence to treatment in this study is quite high and it may not distort the analyzed results.

Numerous studies have shown different FeNO levels among patients with asthma with different levels of asthma 


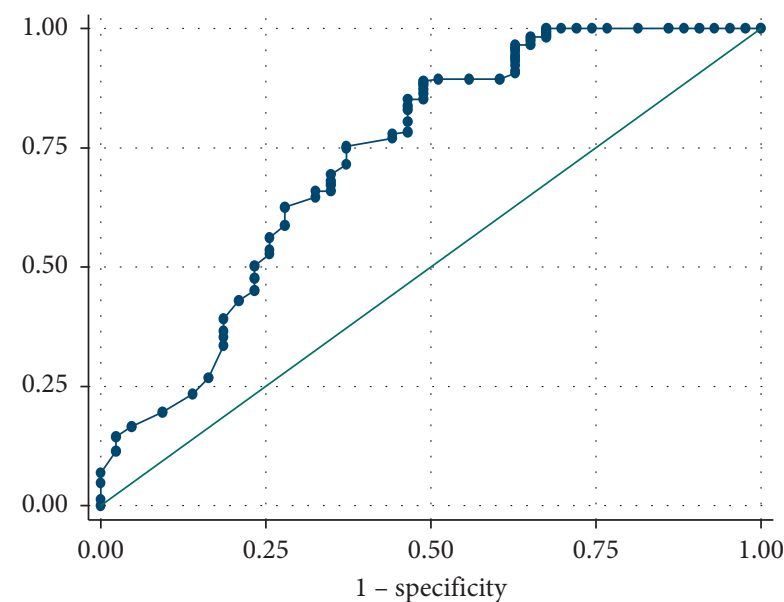

Area under ROC curve $=0.7302$

(a)

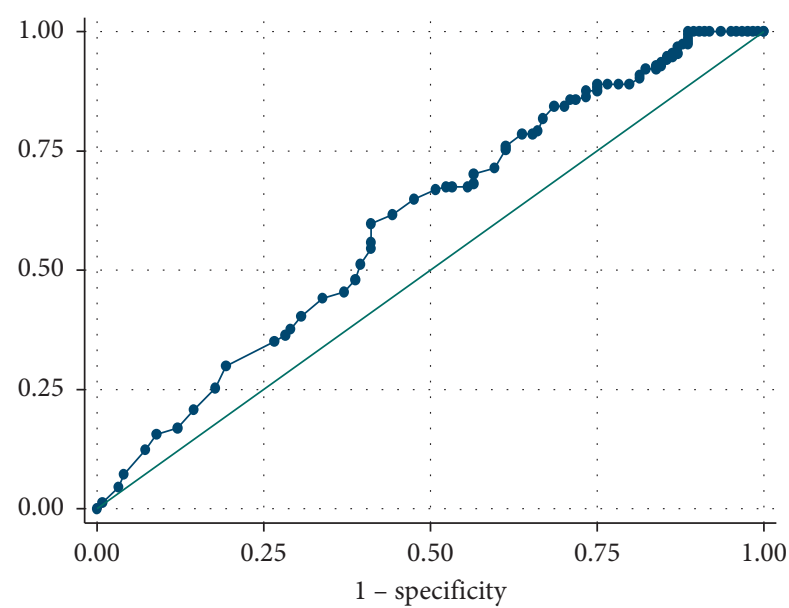

Area under ROC curve $=0.6009$

(b)

FIgure 4: The area under the ROC curve of FeNO in detecting (a) GINA-defined uncontrolled asthma and (b) GINA-defined wellcontrolled asthma.

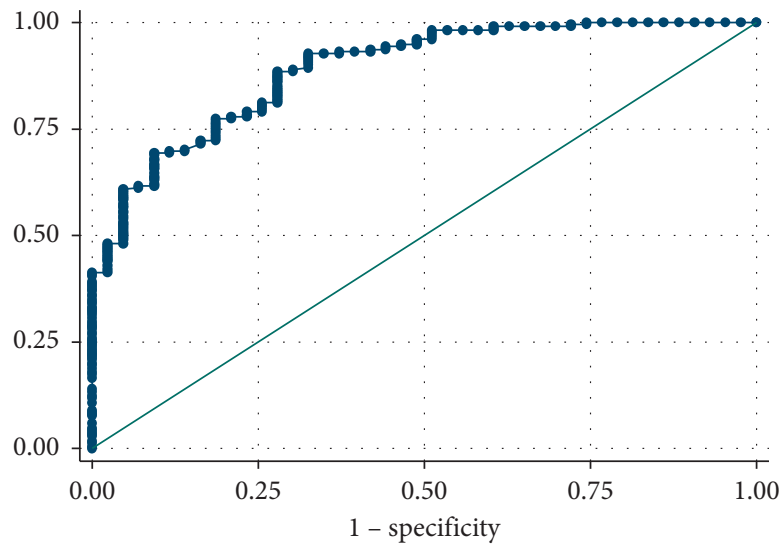

Area under ROC curve $=0.8901$

(a)

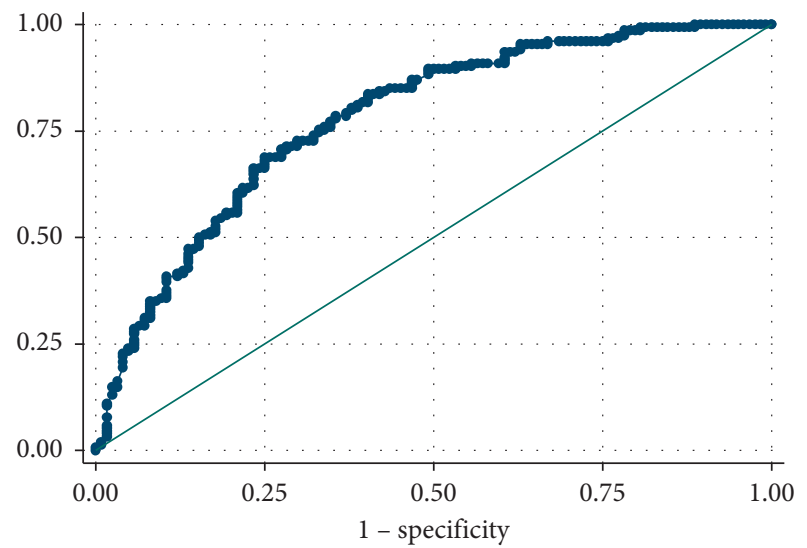

Area under ROC curve $=0.7793$

(b)

FIGURE 5: The area under the ROC curve of combination of FeNO and ACT in detecting (a) GINA-defined uncontrolled asthma and (b) GINA-defined well-controlled asthma.

control defined by GINA, which is shown in Table 6. Nevertheless, the relationship between FeNO level and asthma control status may present in group of untreated patients but not in group of treated patients as reported by Visitsunthorn et al. [13]. Some authors believed that in patients on medium to high dose corticosteroid treatments, the FeNO level alone was not a good indicator for asthma control [6, 13]. Alvarez-Gutiérrez et al. [14] also indicated that an increased FeNO level could correspond to an UC asthma status, but that result was not statistically significant. In addition, FeNO may be useful in evaluating patients with eosinophilic airway inflammation but not in patients with neutrophilic or mixed-type airway inflammation [13-17]. Therefore, FeNO level in the later groups may not reflect asthma control status, which was also confirmed in several studies [13-17]. On the another hand, GINA-defined asthma control was based on patients' information over the preceding four weeks while FeNO measurement reflects inflammation on the day of assessment. Consequently, there could be a disagreement between the two evaluations, which has been observed in previous studies [14, 15, 17] but not in the present study. Because of this reason, it is suggested to use a combination of FeNO level with other measurements such as spirometry or questionnaire for a complete assessment for the asthma control status in patients with asthma since asthma is a heterogeneous disease [18, 19]. In the study of the combination of FeNO and questionnaire related to asthma control, Plaza et al. found that the addition of FeNO to ACQ-7 (asthma control questionnaire) increased the detectability of not-well-controlled asthma (compare to using ACQ-7 alone) [20]. In this study, the authors found that the combination of FeNO to ACQ-7 increased the detection of uncontrolled asthma by $14.8 \%$ following the maintenance therapy adjustment. 
TABLE 4: Cross-table of combination of FeNO and ACT in detecting uncontrolled asthma.

\begin{tabular}{|c|c|c|c|c|}
\hline & & \multicolumn{2}{|c|}{ GINA control status } & \multirow{2}{*}{ Total } \\
\hline & & UC asthma & Controlled asthma* & \\
\hline \multirow{3}{*}{$\mathrm{FeNO}+\mathrm{ACT}$} & UC asthma $(\mathrm{FeNO}>50 \mathrm{ppb}$ and $\mathrm{ACT}<20)$ & 17 & 10 & 27 \\
\hline & Controlled asthma $(\mathrm{FeNO} \leq 50 \mathrm{ppb}$ or $\mathrm{ACT} \geq 20)$ & 26 & 225 & 251 \\
\hline & Total & 43 & 235 & 278 \\
\hline
\end{tabular}

Diagnostic values of combination of FeNO and ACT in detecting uncontrolled asthma calculated from this table are as follows: Sensitivity: $40 \%$, specificity: 96\%, PPV: 63\%, NPV: 90\%, PLR: 10, and NLR: 0.6. Chi-square test, $p<0.001$. UC, uncontrolled; FeNO, fractional exhaled nitric oxide; ACT, asthma control test; PPV, positive predictive value; NPV, negative predictive value; PLR, positive likelihood ratio; NLR, negative likelihood ratio; ${ }^{*}$ included GINA-defined partly controlled and well-controlled asthma.

TABLE 5: Cross-table of combination of FeNO and ACT in detecting well-controlled asthma.

\begin{tabular}{cccc}
\hline & & \multicolumn{2}{c}{ GINA control status } \\
& & WC asthma & Not WC asthma* \\
\hline \multirow{3}{*}{ FeNO + ACT } & WC asthma $($ FeNO $<25 \mathrm{ppb}$ and ACT $\geq 20)$ & 75 & 20 \\
& Not WC asthma $(\mathrm{FeNO} \geq 50 \mathrm{ppb}$ or ACT $<20)$ & 79 & 104 \\
& Total & 154 & 185 \\
\hline
\end{tabular}

Diagnostic values of combination of FeNO and ACT in detecting well-controlled asthma calculated from this table are as follows: Sensitivity: 49\%, specificity: 84\%, PPV: 79\%, NPV: 57\%, PLR: 3, and NLR: 0.6. Chi-square test, $p<0.001$. WC, well-controlled; FeNO, fractional exhaled nitric oxide; ACT, asthma control test; PPV, positive predictive value; NPV, negative predictive value; PLR, positive likelihood ratio; NLR, negative likelihood ratio; *included GINA-defined partly controlled and uncontrolled asthma.

TAвLE 6: FeNO values among groups with different GINA-defined asthma control levels in different studies.

\begin{tabular}{|c|c|c|c|c|c|c|c|}
\hline Author, year & Sample size & Mean/median & WC asthma & PC asthma & UC asthma & Statistical method & $p$ \\
\hline Ferdaous et al., 2012 [21] & 37 & NA & 29.1 & \multicolumn{2}{|c|}{48.2} & NA & $<0.05$ \\
\hline Kim et al., 2015 [22] & 155 & Median & 32.3 & \multicolumn{2}{|c|}{63.7} & Mann-whitney & 0.008 \\
\hline \multirow{2}{*}{ Visitsunthorn et al., 2013 [13] } & 20 (ICS naïve) & Median & 31.8 & 34.1 & 92.0 & Kruskal-wallis & $<0.05$ \\
\hline & 94 (with ICS) & Median & 19.2 & 24.9 & 39.2 & Kruskal-wallis & 0.24 \\
\hline Ricciardolo et al., 2016 [23] & 363 & Mean & NA & NA & 42.90 & NA (mean) & $<0.001$ \\
\hline Kamide et al., 2017 [24] & 128 & Mean & 17.5 & 37.1 & 88.8 & ANOVA & $<0.005$ \\
\hline Kavitha et al., 2017 [25] & 151 & Median & 25.5 & 35 & 40 & NA & $<0.001$ \\
\hline This study, 2017 & 278 & Median & 21.0 & 25.0 & 500 & Kruskal-wallis & $<0.001$ \\
\hline
\end{tabular}

UC, uncontrolled; PC, partly controlled; WC, well-controlled; mean or median of FeNO are shown; NA, not available.

Only a few studies have been conducted to determine an appropriate cut-off point of FeNO level to predict a control status of asthma. Studies usually focus on detecting UC asthma rather than WC asthma because an UC status may lead to a bad prognosis. Early recognition of UC asthma may prevent adverse outcomes by adjusting treatment such as giving more educational intervention about the disease, correcting patients' inhaler technique, or stepping-up treatment following the current guidelines. The cut-off points found in these UC asthma detections ranged from 30 to $45 \mathrm{ppb}$ with the sensitivity of about $67 \%$, the specificity of $66 \%$, and the positive predicted value of $85-88 \%[6,25,26]$. In determining UC asthma, the cut-off point we found is FeNO level $>50 \mathrm{ppb}$ corresponding with the ATS-defined high level of FeNO with the specificity of $89 \%$, which is much higher compared to other studies due to using a higher cutoff point $[13,18,19]$. This is understandable since a higher level of the cut-off point value could provide a lower false positive rate and a higher specificity of the test. If choosing the threshold of FeNO $>50 \mathrm{ppb}$ and ACT $<20$ as UC asthma criterion, this threshold can detect this status with the specificity of $96 \%$ and the PLR of 10 . This high specificity and
PLR means that the combination of FeNO and ACT has high value in recognizing uncontrolled asthma.

Identifying the cut-off point to detect WC asthma is more difficult because many studies found that FeNO levels ranged from 22 to $44 \mathrm{ppb}$ in patients with asthma with a WC status [10]. In the present study, the value of FeNO alone or combination with ACT in detecting well-controlled asthma are not high (the AUC of FeNO alone was 0.60 and the AUC of combination was 0.78 ).

In summary, FeNO seems to be useful to predict $\mathrm{WC}$ and UC asthma in Vietnamese adult asthmatics who were on treatment for asthma. This biomarker can predict UC asthma with a cut-off point of $>50 \mathrm{ppb}$ and WC asthma with a cut-off point of $<25 \mathrm{ppb}$. Additionally, the FeNO level may provide add in information to ACT as a surrogate for asthma control.

The present study has certain limitations. Various factors or comorbidities affect FENO measurements including eczema, atopy, allergic rhinitis, indoor air pollution, outdoor air pollution, and allergen exposure, which were not measured and adjusted for in the analysis. In addition, almost all patients in the current study were receiving ICS therapy, which is well known to affect the levels of FeNO and leading 
to a dose-dependent decrease, which was not adjusted in analysis. Moreover, the study population was limited in one hospital and was an observational study, which may not be representative for a general population of Vietnamese asthmatics. Another limitation is that the advantage of FeNO in asthma management recently is predicting the risk of exacerbation. However, this cross-sectional study did not investigate this issue.

\section{Conclusions}

Our present study showed that FeNO level was related to the levels of asthma control. The cut-off point to identify GINAdefined WC asthma and UC asthma were $<25 \mathrm{ppb}$ and $>50 \mathrm{ppb}$, respectively. Those two cut-off points match with the categorization of ATS in low (25 ppb) and high (50 ppb) FeNO level. The combination of FeNO and ACT providedbetter information regarding asthma control than FeNO alone, and this combination is useful to predict asthma control statuses in Vietnamese asthmatic population.

\section{Data Availability}

The data used to support the findings of this study are available from the corresponding author upon request.

\section{Conflicts of Interest}

The authors declare that they have no conflicts of interest.

\section{Authors' Contributions}

Vinh Nguyen conducted the study. Vinh Nguyen, An Le, and Niels Chavannes analyzed the data and drafted the manuscript. Niels Chavannes edited the manuscript. All authors have reviewed the manuscript. All authors contributed toward data analysis, drafting, and revising the paper, and all agree to be accountable for all aspects of the work.

\section{Acknowledgments}

Niox Mino was donated by Aerocrine.

\section{References}

[1] The Global Initiative for Asthma, GINA Report, Global Strategy for Asthma Management and Prevention, The Global Initiative for Asthma, Fontana, WI, USA, 2016, http:// ginasthma.org/.

[2] M. W. Pijnenburg, E. M. Bakker, W. C. Hop, and J. C. De Jongste, "Titrating steroids on exhaled nitric oxide in children with asthma: a randomized controlled trial," American Journal of Respiratory and Critical Care Medicine, vol. 172, no. 7, pp. 831-836, 2005.

[3] H. L. Petsky, K. M. Kew, C. Turner, and A. B. Chang, "Exhaled nitric oxide levels to guide treatment for adults with asthma," Cochrane Database of Systematic Reviews, vol. 9, 2016.

[4] M. Essat, S. Harnan, T. Gomersall et al., "Fractional exhaled nitric oxide for the management of asthma in adults: a systematic review," European Respiratory Journal, vol. 47, no. 3, pp. 751-768, 2016.

[5] Z. Wang, P. Pianosi, K. Keogh et al., The Clinical Utility of Fractional Exhaled Nitric Oxide (FeNO) in Asthma Management: Comparative Effectiveness Review No. 197, Agency for Healthcare Research and Quality, Rockville, MD, USA, 2017.

[6] A. Michils, S. Baldassarre, and A. Van Muylem, "Exhaled nitric oxide and asthma control: a longitudinal study in unselected patients," European Respiratory Journal, vol. 31, no. 3, pp. 539-546, 2008.

[7] Aerocrine, User Manual 000164 (EPM-000109): version 9, Aerocrine, Oxford, UK, 2014, http://www.niox.com/ Documents/000164-09\%20NIOX\%20MINO\%20User\% 20Manual\%20(US).pdf.

[8] Aerocrine, NIOX MINO External Quality Control User Manual, Aerocrine, Oxford, UK, 2016, http://www.niox.com/ Documents/000164-09\%20NIOX\%20MINO\%20User\% 20Manual\%20(US).pdf.

[9] American Thoracic Society and European Respiratory Society, "ATS/ERS recommendations for standardized procedures for the online and offline measurement of exhaled lower respiratory nitric oxide and nasal nitric oxide, 2005," American Journal of Respiratory and Critical Care Medicine, vol. 171, no. 8, pp. 912-930, 2005.

[10] R. A. Dweik, P. B. Boggs, S. C. Erzurum et al., "An official ATS clinical practice guideline: interpretation of exhaled nitric oxide levels (FENO) for clinical applications," American Journal of Respiratory and Critical Care Medicine, vol. 184, no. 5, pp. 602-615, 2011.

[11] nSpire Health Inc., KoKo ${ }^{\circledR}$ Spirometer: KoKo DigiDoser ${ }^{\mathrm{TM}}$. Operations Guide, nSpire Health Inc., Oberthulba, Germany, 2007, http://respitechservice.com/Files-hold/KoKo\%20User \%20Manual.pdf.

[12] M. R. Miller, J. Hankinson, V. Brusasco et al., "Standardisation of spirometry," European Respiratory Journal, vol. 26, no. 2, pp. 319-338, 2005.

[13] N. Visitsunthorn, P. Prottasan, O. Jirapongsananuruk, and K. Maneechotesuwan, "Is fractional exhaled nitric oxide (FeNO) associated with asthma control in children?" Asian Pacific Journal of Allergy and Immunology, vol. 32, no. 3, pp. 218-225, 2014.

[14] F. J. Alvarez-Gutiérrez, J. F. Medina-Gallardo, P. PérezNavarro et al., "Comparison of the Asthma Control Test (ACT) with lung function, levels of exhaled nitric oxide and control according to the Global Initiative for Asthma (GINA)," Archivos de Bronconeumología, vol. 46, no. 7, pp. 370-377, 2010.

[15] B. Khalili, P. B. Boggs, R. Shi, and S. L. Bahna, "Discrepancy between clinical asthma control assessment tools and fractional exhaled nitric oxide," Annals of Allergy, Asthma \& Immunology, vol. 101, no. 2, pp. 124-129, 2008.

[16] M. Pifferi, A. Bush, G. Pioggia et al., "Monitoring asthma control in children with allergies by soft computing of lung function and exhaled nitric oxide," Chest, vol. 139, no. 2, pp. 319-327, 2011.

[17] R. K. Meena, D. Raj, R. Lodha, and S. K. Kabra, "Fractional exhaled nitric oxide for identification of uncontrolled asthma in children," Indian Pediatrics, vol. 53, no. 4, pp. 307-310, 2016.

[18] T. Grzelewski, W. Stelmach, R. Stelmach et al., "Spirometryadjusted fraction of exhaled nitric oxide allows asthma diagnosis in children, adolescents, and young adults," Respiratory Care, vol. 61, no. 2, pp. 162-172, 2016. 
[19] C. Lopes, J. Fonseca, L. Delgado et al., "Assessing asthma control: questionnaires and exhaled nitric oxide provide complementary information," European Respiratory Journal, vol. 32, no. 5, pp. 1419-1420, 2008.

[20] V. Plaza, D. Ramos-Barbón, A. M. Muñoz et al., "Exhaled nitric oxide fraction as an add-on to ACQ-7 for not well controlled asthma detection," PLoS One, vol. 8, no. 10, Article ID e77085, 2013.

[21] Y. Ferdaous, M. Abouda, M. Triki et al., "Asthma control test (ACT), fractionated exhaled nitric oxide (FeNO) and forced expiratory volume in 1 second (FEV1) correlation in asthma control," European Respiratory Journal, vol. 40, no. 56, 2012.

[22] H. S. Kim, Y. H. Kim, H. S. Lee et al., "Utility of tools for the assessment of asthma control in childhood asthma," Allergy, Asthma \& Respiratory Disease, vol. 3, no. 4, pp. 261-266, 2015.

[23] F. L. M. Ricciardolo, V. Sorbello, R. Bellezza Fontana, I. Schiavetti, and G. Ciprandi, "Exhaled nitric oxide in relation to asthma control: a real-life survey," Allergologia et Immunopathologia, vol. 44, no. 3, pp. 197-205, 2016.

[24] Y. Kamide, T. Tsuburai, Y. Nakamura et al., "Exhaled nitric oxide concentration measured by NO breath correlate with asthma severity," Journal of Allergy and Clinical Immunology, vol. 139, no. 2, Article ID AB200, 2017.

[25] V. Kavitha, A. Mohan, K. Madan, V. Hadda, G. C. Khilnani, and R. Guleria, "Fractional exhaled nitric oxide is a useful adjunctive modality for monitoring bronchial asthma," Lung India, vol. 34, no. 2, pp. 132-137, 2017.

[26] K. Kostikas, A. I. Papaioannou, K. Tanou et al., "Exhaled NO and exhaled breath condensate $\mathrm{pH}$ in the evaluation of asthma control," Respiratory Medicine, vol. 105, no. 4, pp. 526-532, 2011.

[27] M. Schatz, C. A. Sorkness, J. T. Li et al., “Asthma control test: reliability, validity, and responsiveness in patients not previously followed by asthma specialists," Journal of Allergy and Clinical Immunology, vol. 117, no. 3, pp. 549-556, 2006.

[28] V. N. Nguyen, N. Chavannes, L. T. Le, and D. Price, "The asthma control test (ACT) as an alternative tool to global initiative for asthma (GINA) guideline criteria for assessing asthma control in Vietnamese outpatients," Primary Care Respiratory Journal, vol. 21, no. 1, pp. 85-89, 2012. 